\title{
Prevalence of different mold genera and total aflatoxin content in frozen chicken meat and giblets: a health risk assessment study
}

\author{
${ }^{1}$ Abdallah, K.M.E., ${ }^{2,3 *}$ Elhelaly, A.E., ${ }^{4}$ Hebishy, R.M.M., ${ }^{1}$ Darwish, W.S. and \\ ${ }^{5}$ El-Sherbiny, H.M.M. \\ ${ }^{1}$ Food Control Department, Faculty of Veterinary Medicine, Zagazig University, Zagazig 44519, Egypt \\ ${ }^{2}$ Department of Food Hygiene and Control, Faculty of Veterinary Medicine, Suez Canal University, Ismailia \\ 41522, Egypt \\ ${ }^{3}$ Department of Radiology, Frontier Science for Imaging, School of Medicine, Gifu University, Gifu, Japan \\ ${ }^{4}$ Faculty of Veterinary Medicine, Zagazig University, Zagazig 44519, Egypt \\ ${ }^{5}$ Educational Veterinary Hospital, Faculty of Veterinary Medicine, Mansoura University, Egypt
}

\section{Article history:}

Received: 21 December 2020

Received in revised form: 6

February 2021

Accepted: 29 April 2021

Available Online: 21

November 2021

Keywords:

Chicken giblets,

Aflatoxin,

Mold contamination,

Health risk assessment

DOI:

https://doi.org/10.26656/fr.2017.5(6).753

\begin{abstract}
This study aimed at investigating the prevalence of different mould genera and total aflatoxins (AFTs) content in the retailed frozen chicken breast, thigh, and giblets, including wings, livers, and gizzards. Furthermore, the estimated daily intakes (EDI) of AFTs were calculated. Aflatoxin-related cancer risks among Egyptian adults and children were further assessed using the margin of exposure (MOE) approach. The obtained results indicated mould contamination of the examined chicken breast, thigh, wings, livers, and gizzards at $40 \%, 30 \%, 25 \%, 70 \%$, and 60\%, respectively. Aspergillus spp. and Penicillium spp. were the most predominant mould genera among the examined samples. Further identification of the isolated Aspergilli revealed that Aspergillus niger and Aspergillus flavus were the dominant Aspergillus spp. AFTs were detected only in $40 \%$ and $25 \%$ of the examined liver and gizzard samples, respectively. Positive correlations between AFTs and total mould counts in both livers and gizzards were observed. Calculation of the EDI and MOE of AFTs via consumption of chicken livers and gizzards revealed that excessive consumption of such products represents a potential risk, particularly among children. Therefore, it is highly recommended to adopt strict hygienic measures during the processing and storage of chicken carcasses and reduce the daily intake of chicken livers and giblets.
\end{abstract}

\section{Introduction}

Chicken meat is considered a rich source of animalderived protein, fat, minerals, and vitamins. Chick giblets such as wings, livers, and gizzards are popular products, particularly among children, for their nutritive value, specific aroma, flavour, and easy preparation and serving (Bordoni and Danesi, 2017).

Freezing is one of the old and standard methods used for long-term meat preservation and food security. Freezing can significantly reduce the microbial spoilage of meat and meat products. However, at the same time, failure to keep constant freezing temperatures might facilitate microbial spoilage, particularly mould growth (Darwish et al., 2016).

Mould contamination of the frozen chicken meat and giblets indicates fluctuation of the freezing temperatures

*Corresponding author.

Email: abdelazimelhelaly@vet.suez.edu.eg; drelhelaly@gmail.com or improper hygienic measures adopted during slaughtering, defeathering, evisceration, and further processing (Aberle et al., 2001). Mould growth on the chicken meat and giblets reduces the keeping quality of such products. Besides, some mould species secrete secondary metabolites known as mycotoxins. Of these, aflatoxins (AFTs) are produced by several fungal species, including Aspergillus flavus and Aspergillus parasiticus (Alcaide-Molina et al., 2009).

AFTs cause massive economic losses worldwide via condemnation of the contaminated products (Darwish et al., 2014). Moreover, AFTs reach the human body via ingestion of contaminated animal products leading to several adverse health effects. AFTs are proved to be linked to several toxicological implications, including toxicity, teratogenicity, and immunosuppressive effects. Furthermore, AFTs are also related to human 
hepatocellular carcinoma (Felizardo and Câmara, 2013). There is scarce information about the dietary intake and health risk assessment of total AFTs among the Egyptian population via ingestion of contaminated chicken meat and giblets.

One primary task of the food safety sector is to confirm wholesome meat and meat products to the population. In light of these facts, the current investigation aimed to examine the mold contamination of the retailed frozen chicken meat and giblets. Furthermore, the total AFTs in the studied samples were estimated. AFTs-dietary intake and their possible health risks for the Egyptian population were further calculated.

\section{Material and methods}

\subsection{Collection of samples}

A hundred samples of retailed chicken meat and giblets were collected randomly and equally from the grocery stores in Zagazig city, Egypt. The examined samples were chicken breast, thigh, wings, livers, and gizzards $(\mathrm{n}=20$ each). The collected samples were transferred cooled directly without delay to the Food Control Laboratory, Faculty of Veterinary Medicine, Zagazig University, Egypt for the mycological examination.

\subsection{Mycological examinations}

\subsubsection{Sample preparation}

Samples were prepared according to American Public Health Association (APHA) (2001). In brief, $10 \mathrm{~g}$ of each sample were homogenized in $90 \mathrm{~mL}$ of $0.1 \%$ sterile buffered peptone water (LAB104, LAB M, UK) for 1-2 mins at $2000 \mathrm{rpm}$ using sterile meat homogenizer (type M-p3-302, mechanic, precyzina, Poland). Then, the preparation of ten-fold decimal serial dilutions was followed.

\subsubsection{Determination of total mould count}

Total mould counts (TMC) were determined on both malt extract agar media for ordinary molds and CzapeckDox agar with $5 \% \mathrm{NaCl}$ for xerophilic moulds (Oxoid, Basingstoke, UK), followed by incubation at $25^{\circ} \mathrm{C}$ for 5 7 days. The plates were examined daily for mould growth. TMC was obtained by direct counting of the cultured plates (APHA, 2001).

$\mathrm{TMC} / \mathrm{g}=$ average No. of colonies $\times$ reciprocal of the dilution

\subsubsection{Identification of the isolated moulds}

The protocol of Pitt and Hocking (2009) for the identification of moulds was followed. The colonies' identification was carried using the macroscopical and microscopical characteristics of the mould colonies. The cultures were examined daily for the rate and pattern of growth during the incubation period. The consistency of the surface growth and folding, the colony margins, and the surface and reverse pigmentation were observed. Both the surface and backside of the colonies were examined. For instance, the key features for the conidial heads of $A$. niger are large, dark brown to black, globose, radiate and biseriate. Conidia are brown and roughwalled. Aspergillus flavus colonies are granular, flat, often with radial grooves, yellow at first but quickly becoming bright to dark yellow-green with age. Penicillium is frequently greenish colonies and simple conidiophores supporting phialides in brush-like clusters. Alternaria has a brownish conidiophore that may be straight or flexuous and the conidia are smooth brownish with or without short beaks. The colonies of Cladosporium are greenish to black with black colour in the reverse, and slow-growing.

\subsection{Estimation of total aflatoxins}

Quantitative estimation of the AFs was conducted using Series-4EX Fluorometer (VICAM, Milford, USA) according to previous methods (El-Ghareeb et al., 2013; Abd-Elghany and Sallam, 2015) with slight modifications. In short, $25 \mathrm{~g}$ of each sample was mixed with $5 \mathrm{~g} \mathrm{NaCl}$, then blended in $100 \mathrm{~mL}$ methanol: water (4:1) at high speed for 3 mins. The mixture was diluted 4 times with double-distilled water and filtrated using a 1.5 $\mu \mathrm{m}$ glass microfiber filter. Then, $4 \mathrm{~mL}$ of the filtrate was passed through AflaTest ${ }^{\circledR}-\mathrm{P}$ affinity column at a rate of 2 drops/s. Aflatoxin was eluted from the affinity column using HPLC grade methanol at a rate of $1 \mathrm{drop} / \mathrm{s}$ and collecting all of the samples elute $(1 \mathrm{~mL})$ in a glass cuvette (VICAM part \# 34000). AflaTest ${ }^{\circledR}$ Developer was added to the cuvette at $1.0 \mathrm{~mL}$ and mixed well with the eluate. Then, the cuvette was placed in the calibrated fluorometer. The detection range for the AflaTest was 0.1 (low detection)-300 (high detection) ng/g. The limit of detection (LOD) for all examined matrices was $0.1 \mathrm{ng} / \mathrm{g}$. The wavelength set for the fluorimeter was excitation at $360 \mathrm{~nm}$, and emission at $440 \mathrm{~nm}$.

\subsection{Estimated daily intake (EDI)}

The estimated daily intake (EDI) of AFTs was calculated (Health Canada, 1995) based on the following equation:

$$
\mathrm{EDI}=\mathrm{C} \times \mathrm{F}_{\mathrm{IR}} / \mathrm{BW}
$$

Where EDI is calculated as $\mu \mathrm{g} / \mathrm{kg} /$ day; $\mathrm{C}$ is the concentration of AFTs; $F_{I R}$ is the ingestion rate of chicken meat and giblets, which was set at $150 \mathrm{~g} /$ day (Taha, 2004); BW is the body weight, which was estimated at $70 \mathrm{~kg}$ for adults and $30 \mathrm{~kg}$ for children. 
AFTs content in the examined samples was evaluated according to Lerda (2011). The established MPL for AFTs in meat was set at $4 \mathrm{ng} / \mathrm{g}$.

\subsection{Health risk assessment}

The daily intake of AFTs via ingestion of contaminated chicken meat and giblets was used to assess cancer risk among the Egyptian population, using a margin of exposure (MOE) approach (European Food Safety Authority (EFSA), 2005; FAO/WHO, 2006). MOE is the ratio between the benchmark dose that causes a $10 \%$ increase in the incidence of cancer in the fisher rats (BMDL10) and the average level of the total intake in humans. The BMLD10 for AFTs was estimated to be $250 \mathrm{ng} / \mathrm{kg}$ body weight/day. MOE was calculated according to Benford et al. (2010) from the following equation:

$$
\mathrm{MOE}=\mathrm{BMDL} 10 / \text { total intake }
$$

MOE values lower than 10000 represent a major health concern (EFSA 2020).

\subsection{Statistical analysis}

All values are expressed as means $\pm \mathrm{SE}$, and all measurements were carried out in duplicates. Microbial counts were converted into base logarithms of colonyforming units per gram $(\log \mathrm{CFU} / \mathrm{g})$. Statistical significance was evaluated using a one-way analysis of variance (ANOVA), followed by the Tukey-Kramer HSD post hock test. Pearson's correlations between AFTs and total mold counts in the livers and gizzards were calculated. In all analyses, $p<0.05$ was considered as an indication of statistical significance.

\section{Results and discussion}

The obtained results in the present study revealed clear mould contamination of the frozen chicken meat and giblets. Livers had the highest mould contamination rate at $70 \%$, followed by gizzards at $60 \%$, breast at $40 \%$, thigh at $30 \%$, and wings at $25 \%$ (Figure 1a). In agreement with the prevalence rates of mould contamination, livers had the highest TMC $(\log 10 \mathrm{cfu} / \mathrm{g})$ (2.86 \pm 0.11$)$, followed by the gizzards $(2.49 \pm 0.10)$, breast $(2.33 \pm 0.15)$, thigh $(2.32 \pm 0.08)$, and wings $(2.12 \pm 0.04)$ (Figure 1b). In general, meat and edible offal should be free from moulds according to FAO/WHO (2003). Mould contamination of the retailed meat and edible offal was reported worldwide such as in Italy (Iacumin et al., 2009), Spain (Martín-Sánchez et al., 2011), and Egypt (Darwish et al., 2016). Contamination of the retailed chicken meat and giblets with moulds indicates inadequate hygienic practices adopted during slaughtering, defeathering, evisceration, storage, and distribution. Such sanitary conditions and facilities of the slaughterhouses, butchery shops, freezing rooms, and stores are critical factors for mold contamination (Mizakova et al., 2002).

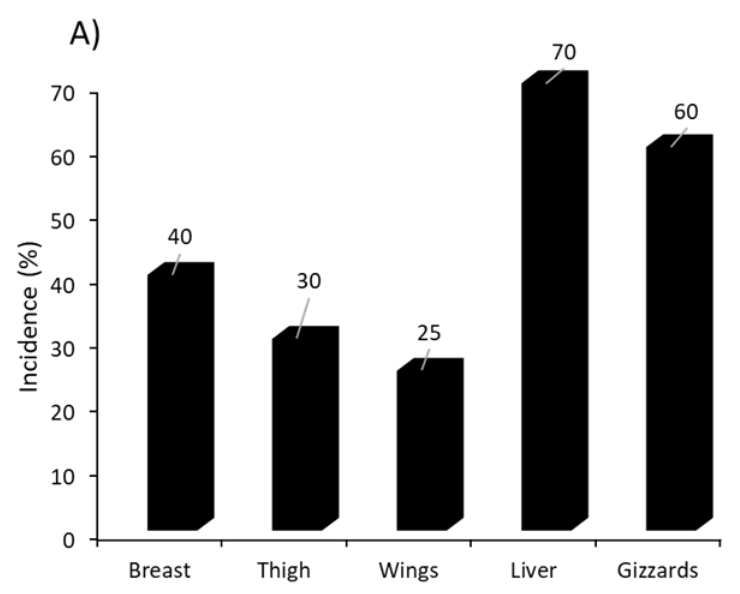

B)

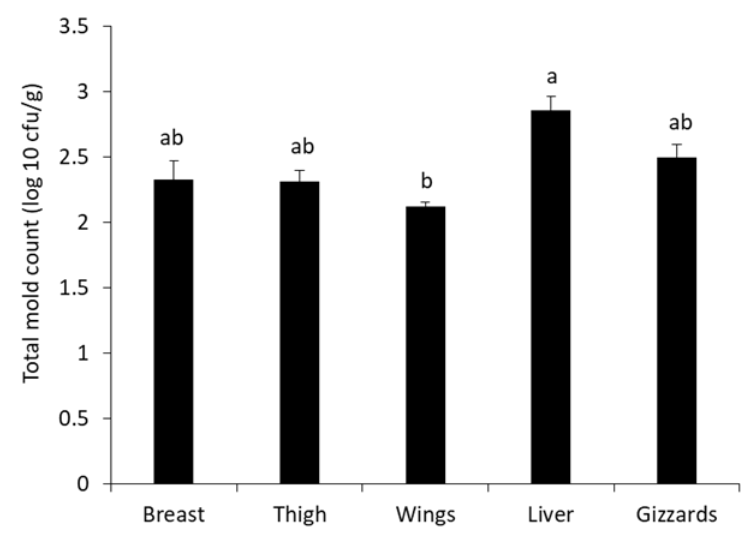

Figure 1. A) Prevalence (\%) of mould contamination, B) total mould count in chicken meat and giblets. Values represent means $\pm \mathrm{SE}(\log 10 \mathrm{CFU} / \mathrm{g})$. Bars with different notations are significantly different at $\mathrm{p}<0.05$.

The identified mould genera in the examined samples were Aspergillus spp., Penicillium spp., Mucor spp., Alternaria spp. and Cladosporium spp. Aspergillus spp. was further identified into A. niger, A. flavus, $A$. fumigatus, and $A$. ochracous. These mold genera and species were isolated at variable percentages as indicated in Figure 2. The most predominant mold genera in the present study were Aspergillus spp. and Penicillium spp. This could be due to their ability to grow over a wide range of temperatures besides they need a very low concentration of oxygen for growth as well as spore germination (Plahar et al., 1991). Cladosporium spp. have the ability to survive at severe adverse conditions such as low temperatures of up to $-7^{\circ} \mathrm{C}$ and minimal water activity $\left(\mathrm{a}_{\mathrm{w}} ; 0.85\right)$ (Jay 2000). Mucor spp. and Alternaria spp. are considered airborne mycoflora and they have the ability to grow over a wide range of temperatures from -3 to $35^{\circ} \mathrm{C}$, particularly in highmoisture foods (Cappuccino and Sherman, 2005). A. niger and A. flavus were the dominant Aspergilli. It is 
noteworthy that A. flavus is one of the major aflatoxigenic moulds. In agreement with the obtained results in the current investigation, Darwish et al. (2016) isolated four mould genera, namely, Aspergillus spp., Penicillium spp., Cladosporium spp., and Alternaria spp. from frozen chicken giblets and meat cuts.

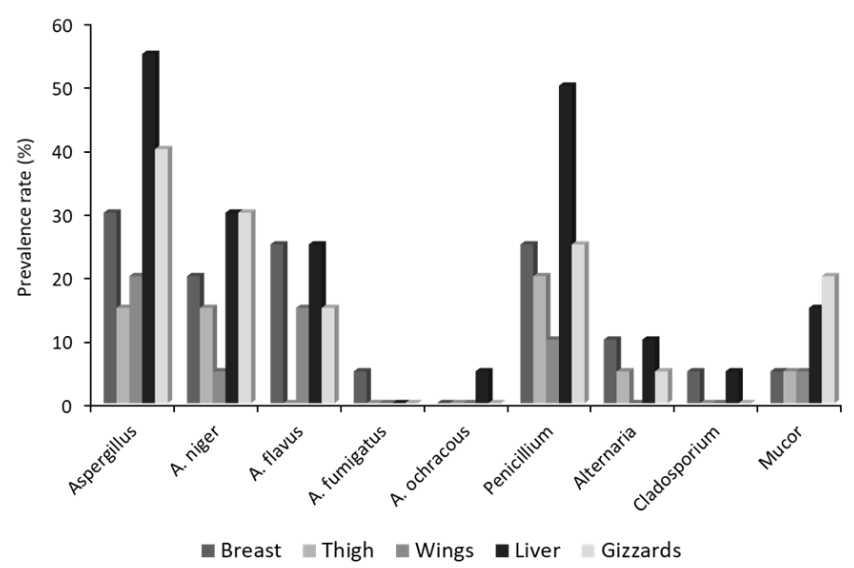

Figure 2. Prevalence rate (\%) of different mould genera in the examined chicken meat and giblets.

AFTs were detected only in $40 \%$ and $25 \%$ of the examined livers and gizzards, respectively (Figure 3A). Mean residual concentrations of total AFTs $(\mathrm{ng} / \mathrm{g})$ in these samples were $1.11 \pm 0.09$, and $1.38 \pm 0.17$ in the examined livers and gizzards, respectively (Figure 3B). Drawn scatter plots between total mould counts and content of AFTs revealed positive correlations in the livers $\left(\mathrm{R}^{2}=0.74\right)$, and gizzards $\left(\mathrm{R}^{2}=0.58\right)$ (Figure $4 \mathrm{~A}$, B). Such positive Pearson's correlation values between the mould contamination and AFTs production reflected the co-occurrence of mould growth and their metabolites. This finding agrees with the previous reports in South Africa, Poland, Argentina, and Uruguay (Mngadi et al., 2008; Cegielska-Radziejewska et al., 2013; Greco et al., 2014; Del Palacio et al., 2016).

Ingestion of foods contaminated with AFTs represents a great hazard to human health. Especially that the repetitive small concentrations of AFTs are highly associated with liver damage and carcinogenesis (Darwish et al., 2014). The recorded concentrations of the total AFTs in the examined samples were within the established MPL. We further calculated the EDI values of AFTs among adults and children via ingestion of contaminated livers and gizzards (Table 1). The obtained results indicated that EDI values (ng/day) for total AFTs were 2.38 (adults) and 3.71 (children) via consumption of chicken livers, and 2.96 (adults) and 4.60 (children) via consumption of chicken gizzards. The MOE approach was further used to estimate the cancer risk for AFTs among the Egyptian population. MOE was considered the most accurate and informative approach to assess the cancer risk for AFTs (EFSA, 2005; FAO/
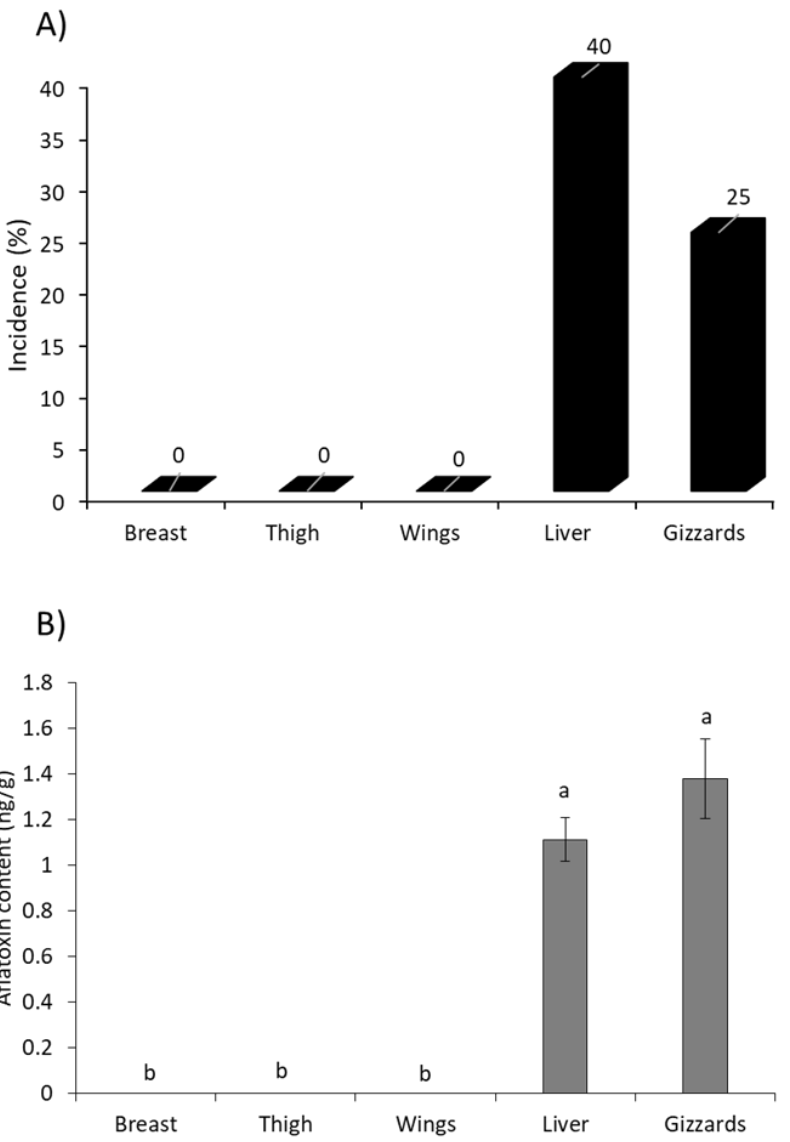

Figure 3. A) Prevalence (\%), B) total aflatoxin residues (ng/g) in the examined chicken meat and giblets. Values represent means \pm SE $(\log 10 \mathrm{CFU} / \mathrm{g})$. Bars with different notations are significantly different at $\mathrm{p}<0.05$.

A)

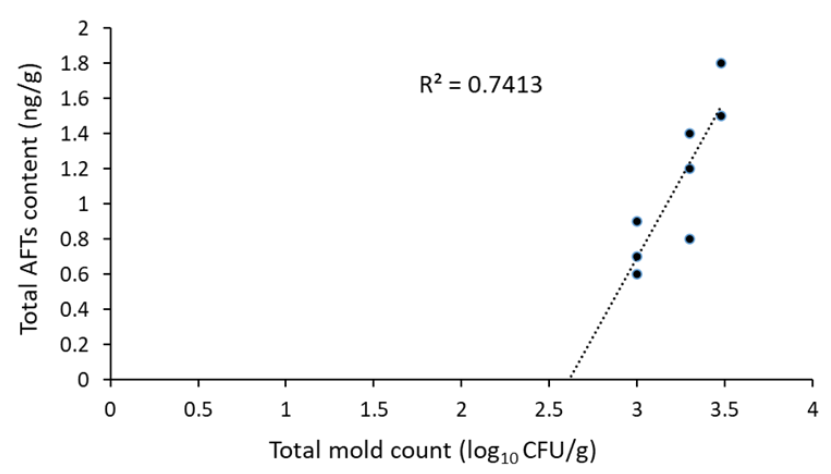

B)

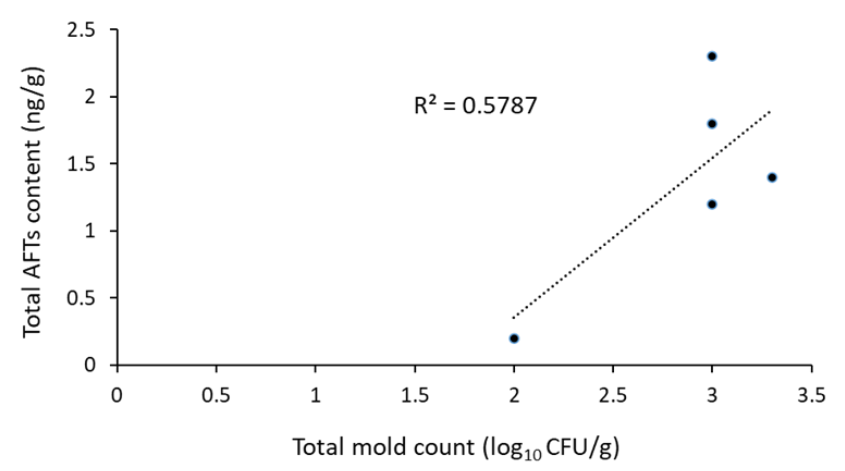

Figure 4. Pearson's correlations between total mould count and total aflatoxin content in the examined chicken livers and gizzards. Scatter plots were drawn between total mould count and total aflatoxin content in the examined chicken A) livers and B) gizzards 
WHO, 2006). In our study, MOE values of AFTs among adults were 104.87 (livers) and 84.54 (gizzards); while these values for children were 67.42 (livers) and 54.35 (gizzards). As MOE values lower than 10000 represent a major health concern (EFSA 2020), therefore, consumption of these organs in Egypt might indicate potential cancer risk. Likely, Elzupir and Abdulkhair (2020) reported that MOE values were 175, and 311 for total AFTs in the processed beef meat and poultry meat products, respectively indicating a public health concern among the Saudi population.

Table 1. Estimated daily intake and margin of exposure of AFTs among the Egyptian population

\begin{tabular}{ccccc}
\hline & \multicolumn{2}{c}{ EDI } & \multicolumn{2}{c}{ MOE } \\
\cline { 2 - 5 } & Adults & Children & Adults & Children \\
\hline Breast & NA & NA & NA & NA \\
Thigh & NA & NA & NA & NA \\
Wings & NA & NA & NA & NA \\
Liver & 2.38 & 3.71 & 104.87 & 67.42 \\
Gizzards & 2.96 & 4.6 & 84.54 & 54.35 \\
\hline
\end{tabular}

EDI: Estimated daily intake, MOE: Margin of exposure, NA: Not applicable

\section{Conclusion}

The obtained results in the present work indicated the co-occurrence of mould contamination and AFTs production in the frozen chicken livers and gizzards. This might affect the products' safety and quality. Therefore, strict hygienic precautions should be taken during the handling of chicken meat and giblets during handling, processing, and storage.

\section{References}

Abd-Elghany, S.M. and Sallam, K.I. (2015). Rapid determination of total aflatoxins and ochratoxins A in meat products by immuno-affinity fluorimetry. Food Chemistry, 179, 253-256. https:// doi.org/10.1016/j.foodchem.2015.01.140

Aberle, E.D., Forrest, J.C., Gerrard, D.E. and Mills, E.W. (2001). Principles of Meat Science. $4^{\text {th }}$ ed. Dubuque, Iowa, USA: Kendall/ Hunt Publishing Co.,

Alcaide-Molina, M., Ruiz-Jiménez, J., Mata-Granados, J.M. and Luque de Castro, M.D. (2009). High through-put aflatoxin determination in plant material by automated solid phase extraction on-line coupled to laser-induced fluorescence screening and determination by liquid chromatography-triple quadrupole mass spectrometry. Journal of Chromatography A, 1216(7), 1115-1125. https:// doi.org/10.1016/j.chroma.2008.12.049

American Public Health Association (APHA). (2001). Compendium of methods for the microbiological examination of food. $4^{\text {th }}$ ed. Washington, DC, USA:
American Public Health Association.

Benford, D., Bolger, P.M., Carthew, P., Coulet, M., DiNovi, M., Leblanc, J-C., Renwick, A.G., Setzer, W., Schlatter, J. and Smith, B. (2010). Application of the Margin of Exposure (MOE) approach to substances in food that are genotoxic and carcinogenic. Food and Chemical Toxicology, 48 (Suppl 1), S2-S24. https://doi.org/10.1016/ j.fct.2009.11.003

Bordoni, A. and Danesi, F. (2017). Poultry meat nutritive value and human health, Chapter 11 - In Woodhead Publishing Series in Food Science, Technology and Nutrition, Poultry Quality Evaluation, p. 279-290. USA: Woodhead Publishing. https://doi.org/10.1016/ B978-0-08-100763-1.00011-8

Cappuccino, J. and Sherman, N. (2005). Microbiology: A laboratory manual textbook. 7th ed. California, USA: Benjamin Cummings.

Cegielska-Radziejewska, R., Stuper-Szablewska, K. and Szablewski, T. (2013). Microflora and mycotoxin contamination in poultry feed mixtures from western Poland. Annals of Agricultural and Environmental Medicine, 20(1), 30-35.

Darwish, W.S., El-Bayomi, R.M., El-Moaty, A.M.A. and Gad, T.M. (2016). Mould contamination and aflatoxin residues in frozen chicken meat-cuts and giblets. Japanese Journal of Veterinary Research, 64 (Supplement 2), S167-S171. https://doi.org/10.1292/ jvms.13-0563

Darwish, W.S., Ikenaka, Y., Nakayama, S.M. and Ishizuka, M. (2014). An overview on mycotoxin contamination of foods in Africa. Journal of Veterinary Medical Sciences, 76(6), 789-797. https:// doi.org/10.1292/jvms.13-0563

Del Palacio, A., Mionetto, A., Bettucci, L. and Pan, D. (2016). Evolution of fungal population and mycotoxins in sorghum silage. Food Additives and Contaminants Part A Chemistry, Analysis, Control, Expours and Risk Assessment, 33(12), 1864-1872. https://doi.org/10.1080/19440049.2016.1244732

El-Ghareeb, W.R., Darwish, W.S., Tharwat, A.E., ElDesoky, K.I. and Hussein, M.A. (2013) Aflatoxin and ochratoxin A residues in some meat additives. Life Science Journal, 10(4), 3411-3417.

Elzupir, A.O. and Abdulkhair, B.Y. (2020). Health risk from aflatoxins in processed meat products in Riyadh, KSA. Toxicon, 181, 1-5. https:// doi.org/10.1016/j.toxicon.2020.04.092

Lerda, D. (2011). Mycotoxins fact sheet. $4^{\text {th }}$ ed. Retrieved from European Commission website: https://ec.europa.eu/jrc/sites/jrcsh/files/Factsheet\% 20Mycotoxins_2.pdf 
European Food Safety Authority (EFSA) (2020) Opinion of the scientific committee on risk assessment of aflatoxin in foods. European Food Safety Association Journal, 18(3), e06040.

European Food Safety Authority (EFSA). (2005). Opinion of the scientific committee on a request from EFSA related to a harmonized approach for risk assessment of substances which are both genotoxic and carcinogenic. European Food Safety Association Journal, 282, 1-31. https://doi.org/10.2903/ j.efsa.2005.282

FAO/WHO. (2003) Working paper on elaboration of regional standard for microbiological levels in food. Cairo, Egypt. Retrieved from FAO website: http:// www.fao.org/tempref/codex/Meetings/CCNEA/ ccnea2/NE03_16e.pdf

FAO/WHO. (2006). Evaluation of Certain Food Contaminants. Sixty-fourth Report of the Joint FAO/WHO Expert Committee on Food Additives. World Health Organization, Geneva (WHO Technical Report Series, No. 930. Retrieved from WHO website: http://hqlibdoc.who.int/trs/ WHO_TRS_930_eng.pdf.

Felizardo, R.J.F. and Câmara, N.O.S. (2013). Hepatocellular carcinoma and food contamination: Aflatoxins and ochratoxin A as great prompter. World Journal of Gastroenterology, 19(24), 37233725. https://doi.org/10.3748/wjg.v19.i24.3723

Greco, M.V., Franchi, M.L., Rico Golba, S.L., Pardo, A.G. and Pose, G.N. (2014). Mycotoxins and mycotoxigenic fungi in poultry feed for foodproducing animals. The Scientific World Journal, 2014, 968215. https://doi.org/10.1155/2014/968215

Health Canada (1995). Investigating human exposure to contaminants in the environment: A handbook for exposure calculations. Retrieved from website: http://www.ap.smu.ca/ lcampbel/

Handbook_ExposureCalculations1.pdf

Iacumin, L., Chiesa, L., Boscolo, D., Manzano, M., Cantoni, C., Orlic, S. and Comi, G. (2009). Moulds and ochratoxin A on surfaces of artisanal and industrial dry sausages. Food Microbiology, 26(1), 65-70. https://doi.org/10.1016/j.fm.2008.07.006

Jay, J.M. (2000). Modern Food Microbiology. $6^{\text {th }}$ ed. Gaithersburg, Maryland, USA: Aspen Publisher Inc. https://doi.org/10.1007/978-1-4615-4427-2

Martín-Sánchez, A.M., Chaves-López, C., Sendra, E., Sayas, E., Fenández-López, J. and Pérez-Álvarez, J.A. (2011). Lipolysis, proteolysis and sensory characteristics of a Spanish fermented dry-cured meat product (salchichón) with oregano essential oil used as surface mold inhibitor. Meat Science, 89(1), 35-44. https://doi.org/10.1016/j.meatsci.2011.03.018

Mizakova, A., Pipova, M. and Turek, P. (2002). The occurrence of moulds in fermented raw meat products. Czech Journal of Food Science, 20(3), 8994. https://doi.org/10.17221/3516-CJFS

Mngadi, P.T., Govinden, R. and Odhav, B. (2008). Cooccurring mycotoxins in animal feeds. African Journal of. Biotechnology, 7(13), 2239-2243.

Pitt, J.I. and Hocking, A.D. (2009). Fungi and Food Spoilage, $3^{\text {rd }}$ ed. London: Blackie Academic and Professional. https://doi.org/10.1007/978-0-38792207-2

Plahar, W.A., Pace, R.D. and Lu, J.Y. (1991). Effect of storage condition on the quality of smoked dried herring (Sardinella eba). Journal of the Science of Food and Agriculture, 57(4), 597-610. https:// doi.org/10.1002/jsfa.2740570412

Taha, F. (2004). Derived feed demand for Egypt's poultry and egg sector to 2010-policies and implications. Selected paper prepared for presentation at the Southern Agricultural Economics Association Annual Tulsa, Oklahoma, February 18, 2004. Retrieved from https://core.ac.uk/download/ pdf/7060007.pdf 